\title{
ANALYSIS AND CONTROL OF VIBRATION IN GRINDING MACHINES
}

\author{
AVS.Ganeshraja ${ }^{1}$, T.Dheenathayalan ${ }^{2}$ \\ ${ }^{I}$ PG Scholar, Department of Mechanical Engineering, Knowledge Institute of Technology, Tamilnadu, India \\ ${ }^{2}$ Assistant Professor, Department of Mechanical Engineering, Knowledge Institute of Technology, Tamilnadu, India
}

\begin{abstract}
Vibration in grinding machine is hard to measure. It is witnessed from the formation of waviness on the work piece and grinding wheel. The major causes of vibration in grinding machine are misalignment and unbalancing. These unwanted vibrations will reduce the life of both machine and tool, resulting in loss of production. Vibration measurement is done by different approaches. This paper explains the vibration measurement done by Vibrometer. The vibrations are minimized by introducing dampers, made of rubber. The vibration is isolated due to the elasticity and energy absorbing property of rubber.
\end{abstract}

Keywords: grinding, vibration analysis, damping.

\section{INTRODUCTION}

\subsection{Loss of Accuracy and Productivity}

Now-a-days, Vibration is one of the major problems in grinding operation. In general, vibration is said to be oscillations occurred from a stable position. Accuracy and productivity of the machine are affected due to this vibration. Chattering is one of the reasons for reduced accuracy in the grinding machine.

\subsection{Vibration}

In general, vibration is classified in to two types

i. Forced vibration.

ii. Self- excited vibration.

\subsubsection{Forced Vibration}

Misalignment of grinding wheel is the major cause of the forced vibration. Unbalance and eccentricity of grinding wheel are the other causes of forced vibrations. [Inaskai and Yonetsu 1969, Gawlak 1984]. Hydraulic systems installed in grinding machines will also cause Forced vibration. Floor vibration is also a source of vibration.

\subsubsection{Self - Excited Vibration}

These vibrations are caused from the cutting process in grinding machines. Regenerating effect is the main cause of this vibration. On the rotation of the grinding wheel, there is the chance of formation of waviness between the grinding wheel and workpeice. A characteristic feature of grinding chatter is, however, that such regenerating effect possibly exists on both the work piece and grinding wheel surfaces [Gurney 1965, Inasaki 1977]. There are two types of regenerative vibration as follows:

\section{Work Regenerative Chatter}

Work Regenerative is nothing but the, the vibration waves are generated in the work piece is said to be as work regenerative chatter.

\section{Wheel Regenerative Chatter}

Wheel Regenerative chatter is said to be as, the vibration waves are generated in the grinding wheel.

\subsection{Effect of Work Piece Velocity}

When the velocity of the workpiece is high, a high frequency vibrations are observed in the beginning of the grinding. Due to this vibration surface imperfection noticed on the material. Surface imperfections are mainly due to the regenerative effect, which is due to the presence of vibration on grinding wheels. When the velocity of the material is low, vibration is neglected at the starting of the grinding. As the velocity of the work piece is low, Amplitude increases gradually, surface imperfection is absent.

\subsection{Effects on Vibration}

The machine assembly is disturbed due to the forced and self -excited vibration. Because of this vibration it causes surface errors in grinding wheels and workpiece. The machine tools are damaged partially or fully due to this vibration. Surface finish was affected; this was considered as the major effects in grinding operation. Accuracy of the job is affected. This was mainly due to the chatter vibration. Hand arm vibration is one of the effects for human beings. Hand arm vibration is nothing but the vibrations are enter into human body through the mechanical machines or tools. This hand arm vibration affects the blood flow and reduces the sensation in the fingers. This effect is caused due to the continuous working in grinding operations. 


\section{LITERATURE REVIEW}

1. Nemeth Stefan, Neslusan Mirosla.., (2007) published a paper on the Vibration in Grinding Operations says that the vibrations of grinding operations are carried out by a dynamometer. The measured values were analysed through the FFT analyse. The algorithm which is used in the FFT analyse is the Fast Fourier Transform. This produces the optimum frequency resolution form the machines. It is the suitable technique for identifying the cutting ability of grinding wheels.

2. She Tianli and Yang Xueshan.., (2008) published a paper on the system of vibration signals measurement based on virtual instrument technology which says that the vibrations are analysed on LABVIEW software. The LABVIEW software was developed by the National Instruments Corporation. This software was applied for all type of measurement areas. LABVIEW software was specially made for seismographic observation. This virtual instrument has several advantages.

3. Nemisha Goswami, Dr.K.G.Dave, A.V.Prajapati.., (2013) published a paper on the Vibration Analysis of lathe Machine which says that vibrations are analysed by FFT. By experimentally we can identify the frequency, velocity and acceleration. The machine tool user should predict the depth of cut and spindle rotation to avoid vibration.

4. VaggeeramHariharan \& PSS. Srinivasan.., (2010) published a paper on the Vibration analysis of parallel misaligned shaft with ball bearing system which says that the vibration is caused by misalignment of the machine. Analysis of the vibration is done by dual channel vibration analyser. Vibration amplitudes is reduced by the introduction of flexible coupling in the system.

5. Muhammad Ramzan and Bilmesh Kumar say in their paper on Vibration Damping of Nano particle Reinforced Rubber that rubber is the suitable material for vibration damping because it has the property of elasticity and viscous and this will help to reduce vibration.

\section{EXPERIMENT}

The vibration in grinding machine is measured by vibrometer. Vibrometer is the one of the instruments for measuring vibration. The components of vibrometer are sensor, contact pin, Rubber cap, magnetic holder and display screen. The size of the machine is very small. It is portable and we can use it on any machines. The vibrometer has three modes.

1. Acceleration measurement mode.

2. Velocity measurement mode.

3. Displacement measurement mode.

Velocity measurement mode is the suitable mode for measuring the vibration because velocity is defined as the rate of displacement per unit time. The Value of the velocity is expressed in terms of $\mathrm{mm} / \mathrm{s}$.

\section{WORKING PROCEDURE}

The contact pin in the vibrometer should be touched to the guard of the surface grinding wheel. The hand held sensor is placed on the object for measurement. The sensor should be tightened for its stable position. Then the grinding machine is turned on. When a vibration occurs, sensor in contact pin sensed the vibration signals and it is sent to the display monitor. The display monitor will show the values in $\mathrm{mm} / \mathrm{s}$. The reading obtained for without loading condition is 11 $\mathrm{mm} / \mathrm{s}$. The workpiece is placed on the table for grinding. Again reading is noted in loading condition. The reading obtained for loading condition is $45 \mathrm{~mm} / \mathrm{s}$. These values are compared with vibration severity standards. Based on the severity, Vibrations are controlled by damping method. The vibration severity or criteria are classified into three types.

1. Tendency Management.

2. Similarity Comparison.

3. Absolute value evaluation.

Tendency management is the best evaluation method. The new vibration values are compared with old reference vibration values. Similarity comparison is said to be as, vibration values are compared to similar type of machines. In absolute value evaluation method Vibration severities are compared with ISO standards.

The vibration severity chart is drawn as per the ISO 2372 as shown below.

Table-1: Vibration severity chart

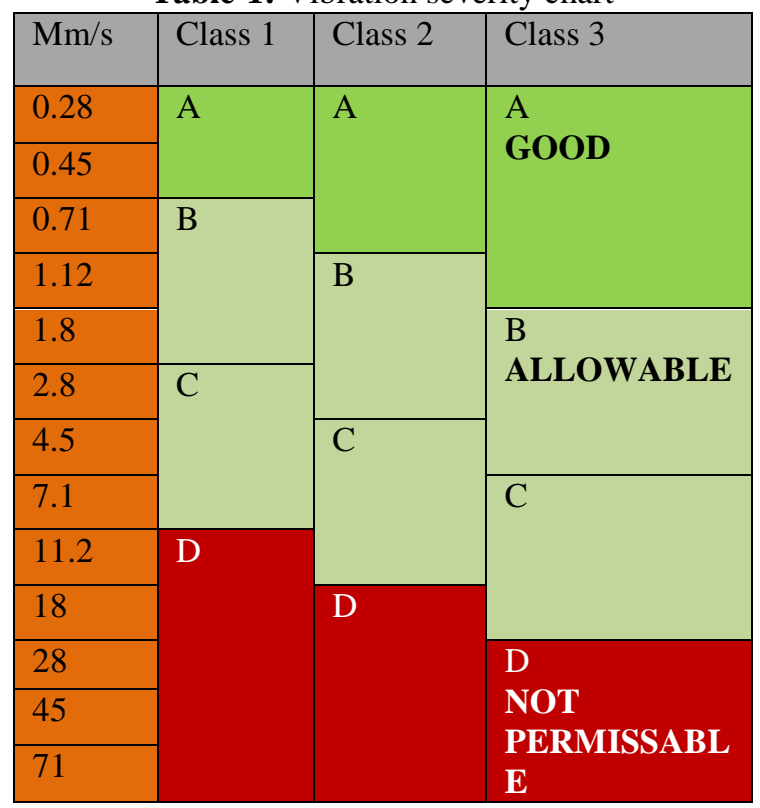

A - Good, B - Acceptable, C - Monitor closely, D Unacceptable.

Table -2: Machine classification

\begin{tabular}{|l|l|}
\hline Class 1 & $\begin{array}{l}\text { An individual part of engine or } \\
\text { machines (up to 15 kilo Watt.) }\end{array}$ \\
\hline Class 2 & $\begin{array}{l}\text { A medium size machine or engine (15 - } \\
\mathbf{7 5} \text { kilowatt motors). }\end{array}$ \\
\hline
\end{tabular}




\begin{tabular}{|l|l|}
\hline Class 3 & $\begin{array}{l}\text { A large size machines or engines such } \\
\text { as heavy motors and flexible } \\
\text { foundation. }\end{array}$ \\
\hline
\end{tabular}

\section{RESULTS AND DISCUSSION}

Control of vibration is done at different approaches. Damping method is one of the vibration controlling techniques in grinding machines. Damping is nothing but the interface between grinding machine and rubber material. The rubber is the essential material for controlling vibration because it has elasticity property and energy absorbing property. Damping characteristics of the rubber compound depends on the dynamic property which are a function of the elastomer. This rubber material was placed below the surface of the grinding machine. Again reading has to be taken for with load and without load. The reading obtained from without load is $2.8 \mathrm{~mm} / \mathrm{s}$ and the reading obtained from with load is $25 \mathrm{~mm} / \mathrm{s}$. Thus the severity of the vibration is reduced by using the damping method.

\section{CONCLUSIONS}

The study reveals that the vibration was measured in grinding machine. This was the one of the major hazards in grinding machines. This study tells that vibration was analysed by the digital vibrometer and controlled by damping method. By implementing above methodologies, we can prevent the loss of accuracy and loss of production. Maintenance also the key factor for these hazards Vibration can be reduced by the periodic maintenance of the machines .If maintenance is done properly, vibration can be detected at initial stage.

\section{REFERENCES}

[1]. NemethStefan, NeslusanMirosola., "Vibration in Grinding Operations", ISSN-1224-3264, 2007

[2]. She Tianli and Yang Xueshan., "The System of Vibration signals Measurement Based on Virtual instrument Technology",

[3]. Vaggeeram Hariharan and PSS.Srinivasan..,"Vibration analysis of parallel misaligned shaft with ball bearing system", journal of Songklanakarin journal of science and technology.Vol-33(1), 61-68, Jan - Feb. 2011

[4]. NemishaGoswami, Dr.K.G.dave, and A.V.Prajapati., "Vibration Analysis of lathe Machine", journal of Global Research Analysis. Vol-2, Issue-5, ISSN NO 2277 - 8160. 